\title{
Application of Failure Assessment Diagram (FAD) for Steel Welded Connection Based on BS7910 and DNV-RP-108
}

\author{
W. Aboalriha
}

\begin{abstract}
The failure assessment diagram (FAD) method has been widely accepted to evaluate the extent to which cracks may affect structural safety. The usage of this FAD method has been validated and included in [1]-[3]. The structure under investigation, described in four fully welded T-joint (BCC5) specimens, where these welded joints are a source of stress concentration and defects from which fatigue cracks can grow. The four specimens were modeled under different displacement loading using a finite element analysis program Ansys and SolidWorks software. In this work, the application of a FAD $\left(L_{r}\right.$, $K r$ ) using maximum stress, cumulative stress ranges, and the last half-cycle stress range was investigated. The results are showing that all the points were lying outside the FAD curve except for the BCC5D specimen point was inside FAD when using maximum stress.

Conclusions made that the cumulative stress gives $L_{r}$ and $K_{r}$ are extremely large and hence predict failure too early. With the Crack Tip Opening Displacement (CTOD) of the test specimen assumed to be about $1 \mathrm{~mm}$ rather than $0.1 \mathrm{~mm}$ it was found that, if a FAD is to be used to indicate failure, then both $L_{r}$ and $K_{r}$ should be based on the maximum stress. It appears that the FAD methodology does help to predict the final failure (which is the usual application in such cases). This represents more effectively the structural behavior and would be more easily used by designers.
\end{abstract}

Key words - BS7910, displacement loading, DVA-P-108, Failure assessments diagram (FAD), Fitness for Service, Integrity assessment, steel welded connection.

\section{INTRODUCTION}

During the last 40 years, various assessment methods were developed based on fracture mechanics. The failure assessment diagram (FAD) approach is widely used to assess a technique followed in recent times. Two mechanisms of failure were identified; brittle fracture and plastic collapse, which are described in [1], [2], [6]-[8]. Fig. 1 shows how the failure assessment curve can be used to interpolate between the above-mentioned failure criteria. The adequacy of the structure can be evaluated by the relative position of the assessment point $\left(L_{r}, K_{r}\right)$ on the FAD [9].

The $\mathrm{X}$-axis and $\mathrm{Y}$-axis of the failure assessment diagram curve use the plastic collapse ratio $\left(L_{r}\right)$ and the brittle fracture ratio $\left(K_{r}\right)$ respectively. The curve contains a plastic collapse cutoff $\left(L_{r \max }\right)$.

The points under the failure assessment diagram curve indicate acceptable cracks (providing suitable safety factors being applied). The evaluation points which fall outside the FAD curve represent unacceptable cracks that indicate a structural failure. This can be useful to determine the predicted critical crack sizes. Therefore, if a specific structural component is analyzed using a given stress-strain curve, then a material-specific FAD can be computed [4], [5].

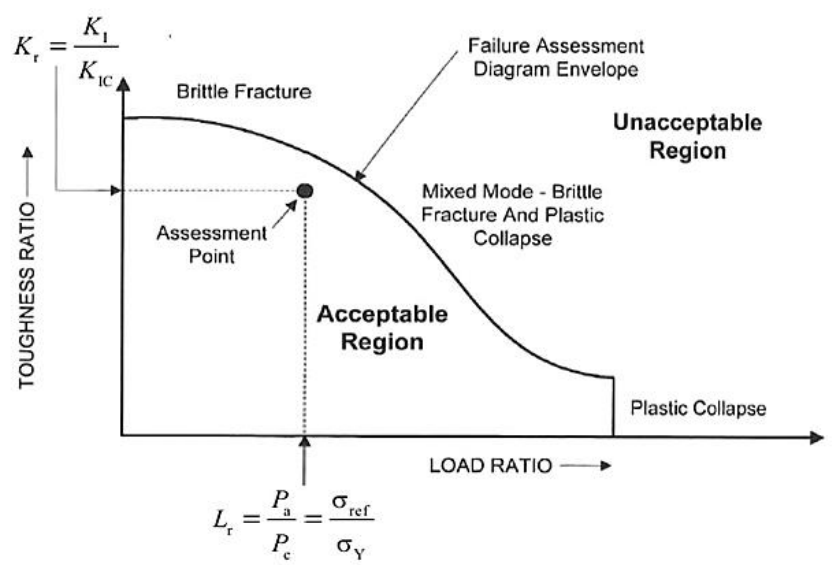

Fig. 1. Flaw assessment using the FAD approach [9].

\section{A. Aims and Objectives}

This research work carried out by the author is aimed at studying the Application of Failure Assessment Diagram (FAD) for steel welded connection based on British Standard BS7910 and pipeline assessment method DET NORSKE VERITAS DNV-RP-F108 using four fully welded T-joint specimens.

\section{LITERATURE REVIEW}

Ainsworth`s 2016 presented assessments of the loads for ductile fracture which are initiated in 21 large-scale piping tests and consisting of 8 straight pipes and 13 elbows [10]. It has been shown that the use of modern solutions for stress intensity factor and limit load recently presented in the literature in conjunction with standard fracture assessment approaches [2], [8], [11]. It leads to generally accurate assessments of the loads for ductile crack initiation, with a tendency for some small conservatism and greater scatter in elbow tests than in straight pipes under bending. Some limited analysis suggests that constraint loss is not a major contributor to the initiation fracture assessments but may have some influence on the ductile crack extension.

For the 6 straight pipes under pure bending, the predicted initiation loads are compared with the experimental initiation loads. Fig. 2 shows the assessment points $\left(L_{r}, K_{r}\right)$ evaluated at 
the experimental and predicted initiation loads, plotted on the FAD. The results show that the assessment points for the predicted loads lie on the failure assessment curve. It can be seen that the predicted initiation loads are close to the experimental loads, with the percentage differences and that ductile initiation occurs before plastic collapse [10].

The assessment points $\left(L_{r}, K_{r}\right)$ of the predicted initiation loads for the other two pipes tested under combined pressure and bending are evaluated using the experimental and predicted loads which are plotted on the FAD as shown in Fig. 2. Hence, iteration is needed to evaluate $L_{r}$ for the applied ratio of pressure and bending. It can be shown that the experimental loads exceed the predicted values by about $30 \%$ and that ductile loading occurs close to plastic collapse.

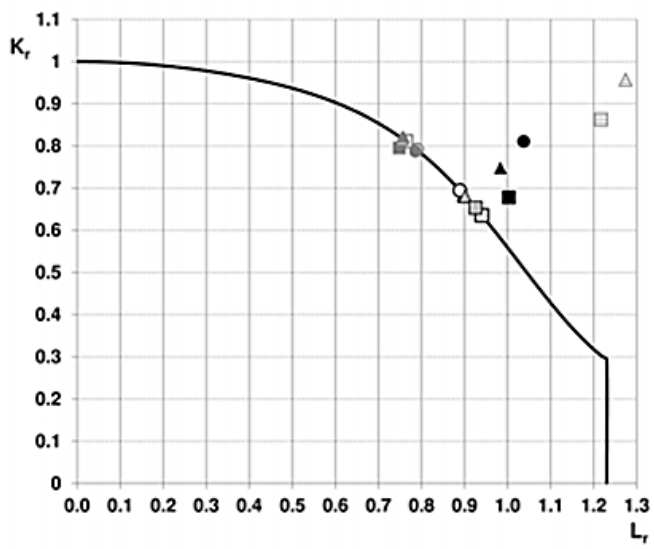

一Option-1 O SPBMTWC8-1 p - SPBMTWC8-1 ex $\triangle$ SPBMTWC8-2p A SPBMTWCB-2 ex - SPBMTWC8-3p - SPBMTWC8-3 SPBMTWC16-1 I SPBMTWC16-1 ex $\triangle$ SPBMTWC16-2P $\triangle$ SPBMTWC16-2 ex SPBMTWC16-3p - SPBMTCG-3 A PASPTWCB-10 $\triangle$ PRSPTWC8.1
$\triangle$ PRSPTWC8.1
ex $\triangle$ PRSPTWC8-3p PRSPTWC8-3 ex

Fig. 2. Circumferentially through-wall cracked. Predicted and experimental initiation load points $(\Delta \mathrm{a}=0.2 \mathrm{~mm})$ on FAD [10].

Fig. 3 and 4 show that the assessment points $\left(L_{r}, K_{r}\right)$ for the 13 elbows under opening mode (crack at extrados) and closing bending (crack at intrados) evaluated at the experimental and predicted initiation loads, plotted on the FAD [10].

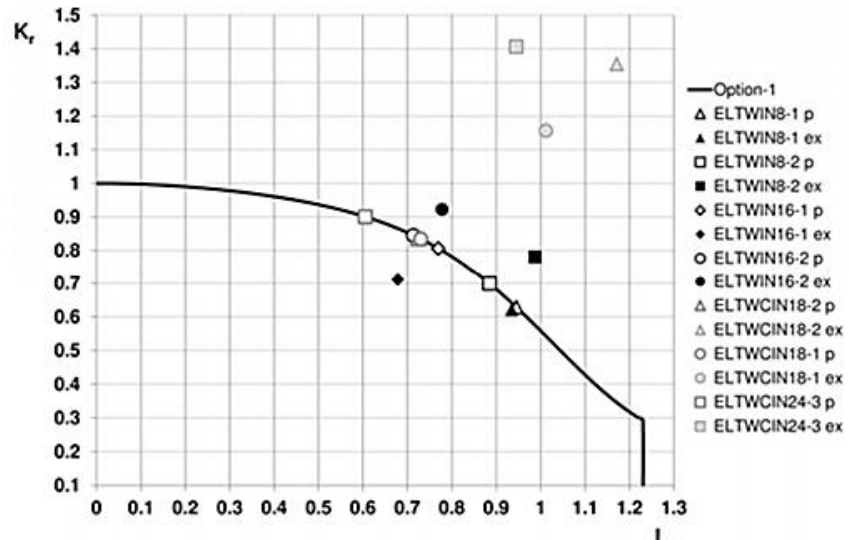

Fig. 3. Circumferentially through-wall cracked elbows under closing mode. Predicted and experimental initiation load points $(\Delta \mathrm{a}=0.2 \mathrm{~mm})$ on FAD under opening mode [10].

British Standard BS7910 specifies the guidance for assessing the acceptability of defects in welded structures based on the FAD method [1], [2]. It specifies three options of fracture assessment:

Option1: is a conservative procedure that is relatively simple to employ and does not require detailed stress/strain data for the materials in hand.

Option 2: is based on the use of a material-specific stressstrain curve.

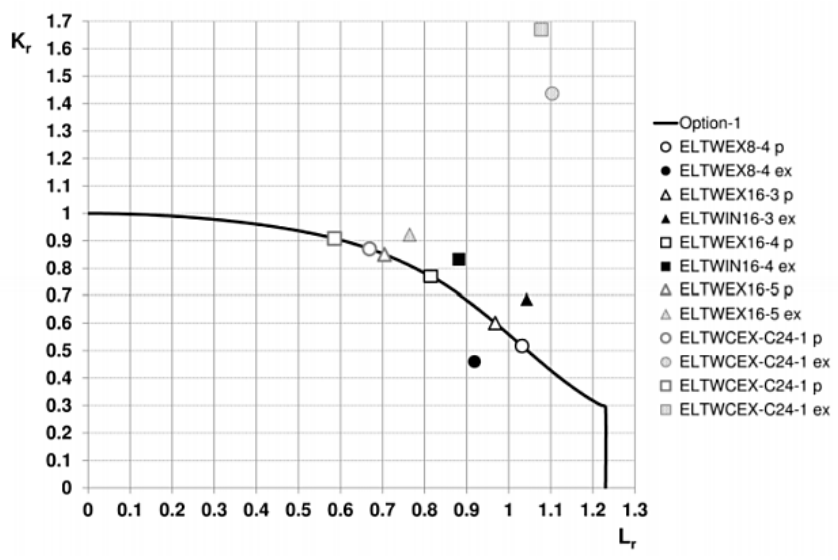

Fig. 4 Circumferentially through-wall cracked elbows under closing mode Predicted and experimental initiation load points $(\Delta \mathrm{a}=0.2 \mathrm{~mm})$ on FAD under closing mode [10].

Option 3: uses numerical analysis to generate a FAD and is not confined to use materials showing ductile tearing [12]. Option 1 and Level 2a, are using (1) to establish FAD curve [1], [2]:

$K_{r}=\left(1-0.14 \mathrm{~L}_{\mathrm{r}}^{2}\right) \times\left[0.3+0.7 \exp \left(-0.5 \mathrm{~L}_{\mathrm{r}}^{6}\right)\right]$

$L_{r}=\sigma_{\mathrm{T}} / \sigma_{\mathrm{y}}$

$K_{r}=\mathrm{K}_{\mathrm{f}} / \mathrm{K}_{\mathrm{c}}$

where:

$L_{r}$ is the load ratio, which is the ratio between the reference stress and the material yield strength.

$K_{r}$ is the toughness ratio, which is the ratio of the stress intensity and the fracture toughness of the material.

Option 2 FAD curves are intended for all types of structures [2].

Hoh`s 2018 tested five (butt-welded) X65 offshore pipe specimens. The (outer diameter $812.8 \mathrm{~mm}$ and $25.4 \mathrm{~mm}$ thickness) were cut into fatigue coupons $(\mathrm{t}=25.4 \mathrm{~mm}, \mathrm{~b}=$ $100 \mathrm{~mm})$. A four-point bending test $(\mathrm{L}=240 \mathrm{~mm}, \mathrm{l}=120 \mathrm{~mm})$ was set up as shown in Fig. 5.

A Finite-element based on a parametric study of four-point bending is used to assess the stress intensity factors (SIFs) of deep surface cracks in X65 specimens. The test specimen (cut from a pipe) was modeled as a plate using the extended finite element method (XFEM) to study the deep flaws in the specimens [13].

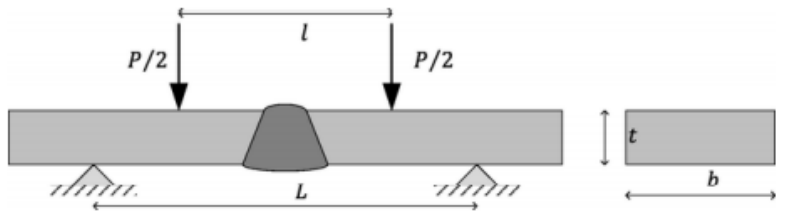

Fig. 5. Four-point fatigue bending setup of X65 steel coupons [13].

The four-point bending fatigue test was conducted at various loads (load ratio 0.1) until the coupons could no longer support fatigue cyclic loading. The load and their corresponding fracture surface were recorded in Table I. 
TABLE I: ASSESSMENT POINTS OF X65 STEEL UNDER BENDING

\begin{tabular}{ccccc}
\hline No & $\begin{array}{c}\text { Stress } \\
\text { Range MPa }\end{array}$ & $\begin{array}{c}\mathrm{K}_{\mathrm{r}} \\
\text { (Free Surface) }\end{array}$ & $\begin{array}{c}\mathrm{K}_{\mathrm{r}} \\
\text { (Deepest Point) }\end{array}$ & $\mathrm{L}_{\mathrm{r}}$ \\
\hline 1 & 292.5 & 0.779 & 0.327 & 0.919 \\
2 & 320 & 0.655 & 0.357 & 0.78 \\
3 & 337.5 & 0.702 & 0.352 & 0.84 \\
4 & 382.5 & 0.603 & 0.354 & 0.787 \\
5 & 450 & 0.520 & 0.310 & 0.672 \\
\hline
\end{tabular}

The effects of limit load solutions and reference stress were used to determine the FAD diagram. The work will employ the effects of limit load solutions and reference stresses were used to the FAD diagram. The work will employ using the Failure Assessment Diagram (FAD) can be used to determine if an existing deep flaw in X65 steel pipe is acceptable by investigating SIFs of a variable depth edge crack that has progressed beyond the specimen width and understanding the effect of plasticity in such large flaws.

The results show that the assessment points are tabulated in Table I and plotted on the FAD as shown in Fig. 6 show that under bending, the cracks on the surface are close to failure or unacceptable, while the points at the crack depth are deemed acceptable.

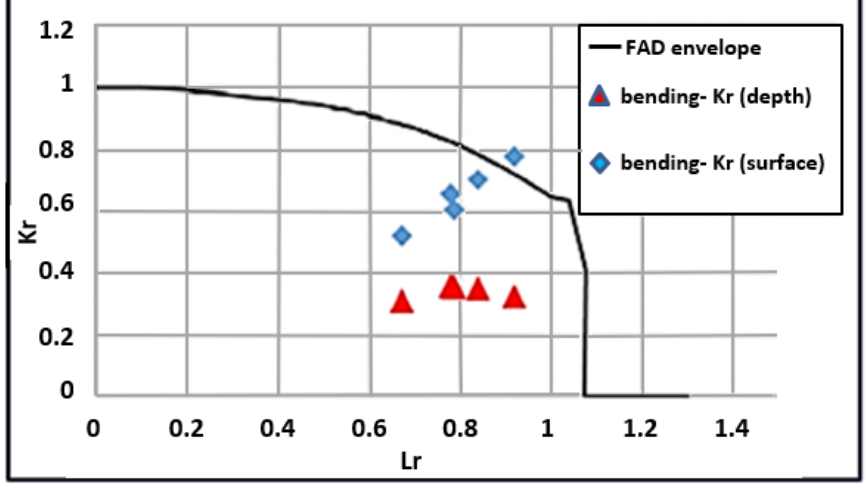

Fig. 6. Failure assessment diagram for X65 with large flaws [13].

They concluded that the current assessment of the tested X65 specimens with large cracks shows local throughthickness yielding is likely to occur before global ligament yielding. This work demonstrates a more accurate approach to assess large flaws by considering the SIFs and limit loads by finite element analysis [13].

Konstantins's 2018 collected 173 test results on pipes with axial flaws from different sources which is analyzed using BS7910 standard, in selected cases, with R6 and/or the API 579-1/ASME FFS-1 standard [14].

The analysis is done to provide validation of BS 7910 and identify where modification is needed. The tests cover a wide variety of parameters, such as geometries (surface, embedded, through the thickness) and loadings (pressure, bending, and residual stress). All the tests are analyzed with the use of the basic assessment option (Option 1), where an arbitrary (1.2) multiplication factor of safety was included in the reference stress solution of axially defected pipes in the BS 7910.The procedure is leading to lower defect tolerance when BS 7910 is used. A modified equation, without this factor of safety, was used in the analysis of the tests, where appropriate, and compared with results from other standards.

They concluded that the comparison between the approaches shows that using a factor of safety with the
BS7910 standard to be unnecessary with all test results $\left(L_{r}\right.$, $K_{r}$ ) points falling outside the FAD, but with less conservatism, as they lie closer to it.

The comparison also shows that the (1.2) factor of safety produces higher $L_{r}$ values, regardless of the geometrical features of the specimens assessed. After the comparison, this generated the initial incentive to investigate this factor of safety. The modification of the BS7910 solution was validated against experimental data. The validation process, which included 173 pipes test data collected from various sources, gave sufficient proof that such a factor is not necessary for BS7910. Therefore, it is recommended that this factor is removed in the coming editions of the standard for higher accuracy in the assessments.

Lie and Pillai's 2019 proposed research to assist in the safety assessment of damaged multi-planar SHS TT, YT, and KT-welded joints. They developed a completely new and robust finite element (FE) mesh generation [15]. The validation is done by comparing the experimental test results with the existing software results.

The results showed that the multi-planar SHS TT, YT, and KT-joints with a low brace to chord width ratio $(\beta)$ are located below the FAD curves comparing to the joints with a higher $\beta$ ratio [2]. This remark is due to the increase of plastic collapse load of cracked of the multi-planar SHS TT, YT, and KT-joints when increasing the value of $\beta$.

It is concluded that the standard Option 1 FAD curve is not always safe in assessing the safety and integrity of cracked multi-planar SHS TT, YT, and KT-joints [2]. A penalty factor of (1.1) is recommended for cracked multi-planar for testing joints. The plastic collapse load of the assessed structure is divided by this factor, so that a conservative value of the plastic collapse load ratio is used to construct the FAD curves. The constructed FAD curves use the safety factor are located above the standard Option 1 FAD curve, thereby providing optimal solutions for cracked multi-planar SHS TT, YT, and KT-joints.

Figs. 7-9 showed that the constructed FAD curves for cracked multi-planar SHS TT, YT, and KT-joints with the newly introduced penalty factor of (1.1). It showed that all the newly constructed FAD curves lie above the standard Option 1 curve [2]. The introduction of the penalty factor of (1.1) guarantees that there are no assessment points, which are located in the intermediate region.

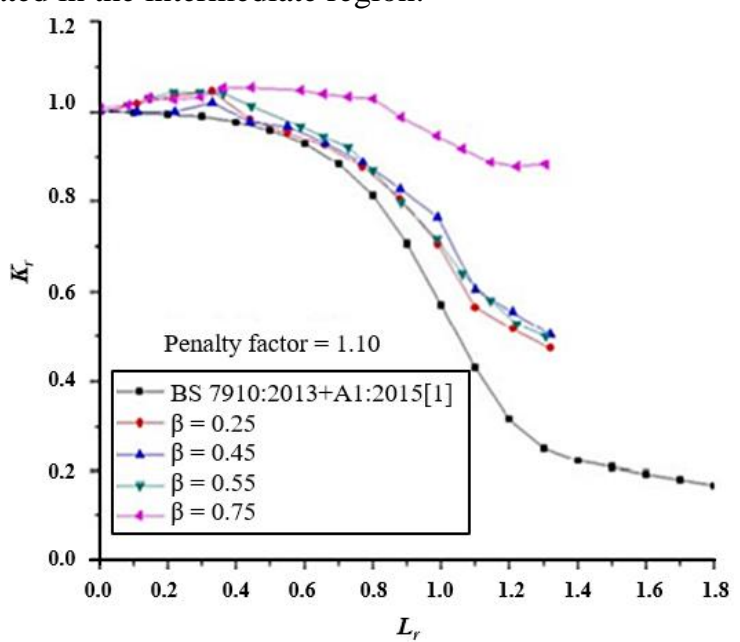

Fig. 7. FAD curves of cracked multi-planar SHS TT- joints with a penalty factor of 1.10 [15] 


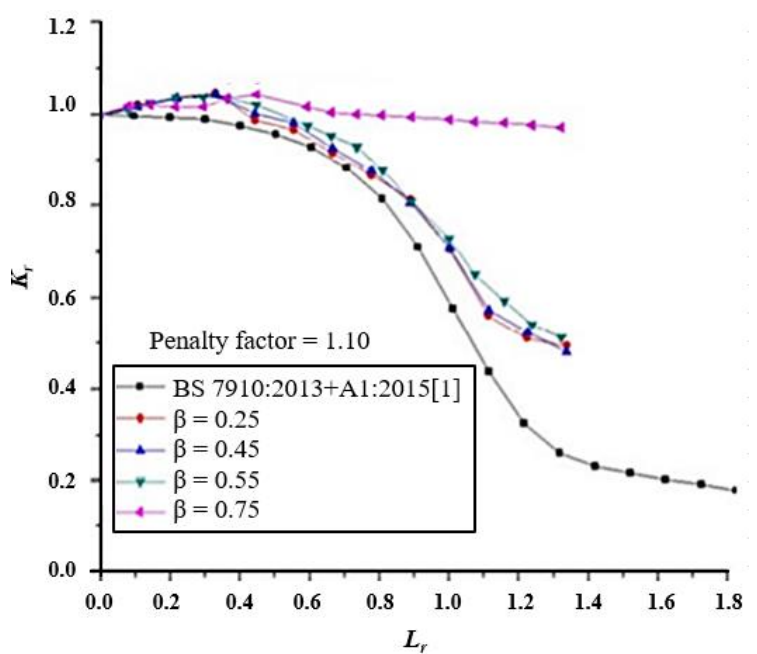

Fig. 8. FAD curves of cracked multi-planar SHS YT-joints with a penalty factor of 1.10 [15].

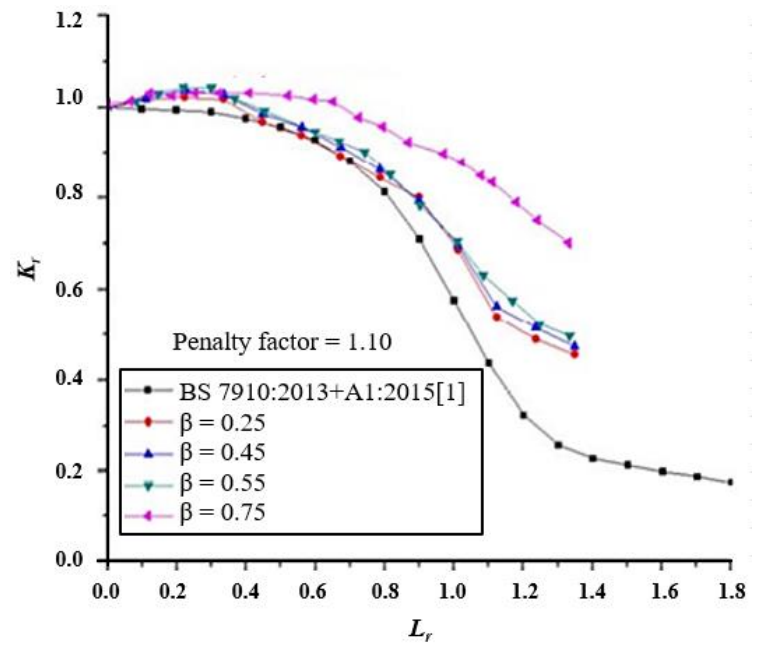

Fig. 9. FAD curves of cracked multi-planar SHS KT-joints with a penalty factor of $1.10[15]$

Montessori's 2020 proposed a combined volumetric technique (VM) based on the extended finite element method (XFEM) to generate the FAD curve to check the safety of a (P264GH) steel gas pipe with a peak internal pressure of $6 \mathrm{MPa}$ [16]. The geometry of their test was modeled with XFEM in a three-dimensional space of the solid type which was established with ABAQUS/CAE with the standard/explicit scheme. The method adopted the properties of this pipe material which are taken from experimental work as shown in Fig. 10 [16]. Their welds strength and ductility make this material appropriate for piping use. The cylinder size was set to $L=625 \mathrm{~mm}, \mathrm{Ri}=193.2 \mathrm{~mm}, \mathrm{R} 0=203.2 \mathrm{~mm}$, $\mathrm{a}=2 \mathrm{~mm}, \mathrm{t}=10 \mathrm{~mm}, \mathrm{c}=4 \mathrm{~mm}$ and $\rho=0.25$.

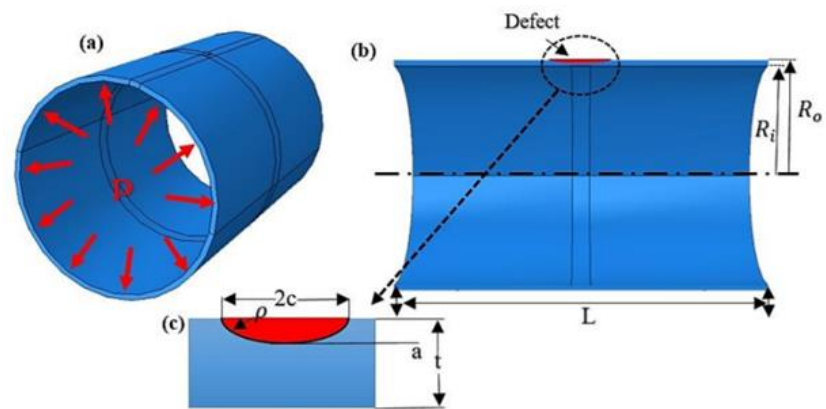

Fig. 10. Schematic of dimension model; (a) Pipe 3D model, (b) dimensions of the geometry model with a defect, (c) characteristics of the defect [16].
Fig. 11 represented the diagram of the FAD curve, which is showing that the assessment point coordinates $\left(S_{r}, L_{r}\right)$ are located in the safety zone. This means that the structure with a defect of $\mathrm{a} / \mathrm{t}=0.2,2 \mathrm{c} / \mathrm{t}=4$ subjected to a pressure of $60 \mathrm{bars}$ is safe.

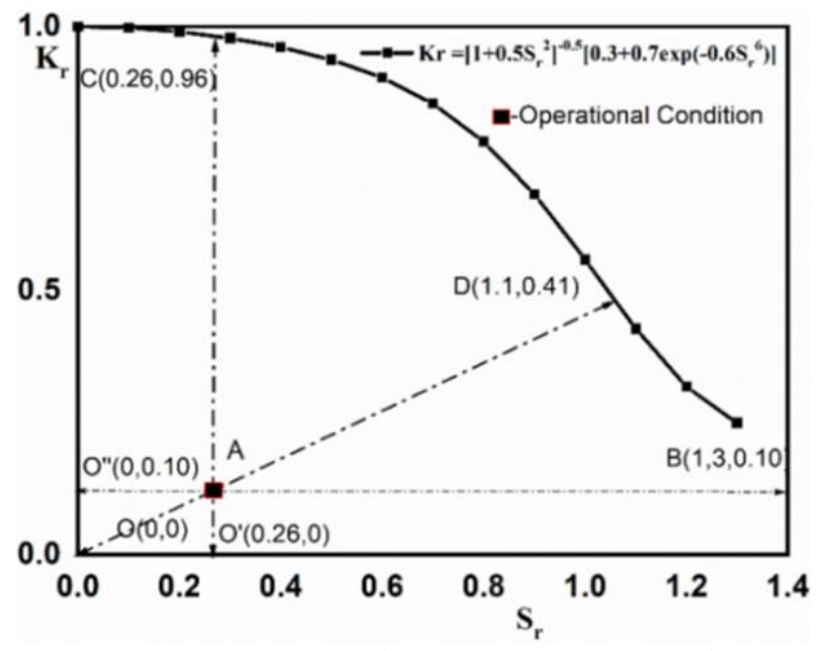

Fig .11. Failure assessment diagram to establish the operational condition [16].

The results indicate that the evaluation of the integrity of a cracked structure can be carried out by combining the XFEM method and the volumetric method. The data obtained from these two methods can contribute to the construction of the FAD diagram. Therefore, the stability of a cracked structure can be examined using the FAD diagram.

\section{RESEARCH WORK RESULTS}

In this work, the fully welded beam to column connection (BCC5) tested under displacement control is described, the beam has a vertical I-section (a typical European beam section IPE300, which is considered equivalent to $\mathrm{W} 12 \times 30$ U.S. wide flange section), and the column is a horizontal Isection (HE160B equivalent to W8 $\times 24$ U.S) as illustrated in Fig. 12 and 13, which were modeled by the author using Solid works and Ansys software as illustrated in Fig. 14 and 15, in conjunction with the test results [17], [Calado 20102014.per.comm]. Validation discussed in detail in the first the Author`s first published paper. This was done by matching the hysteresis loops, maximum high strain, and maximum stress at the crack location of steel joint specimens [19]. The comparison between the analysis and test results showed good agreement. The data obtained from computer analysis was used to establish the application of the failure assessment diagram (FAD).

To determine whether a crack could cause a structural failure, it is necessary to evaluate the FAD point of the existing crack which is found during the inspection. The other alternative approach is to evaluate the end-of-life critical crack size for a fatigue crack growth analysis. 


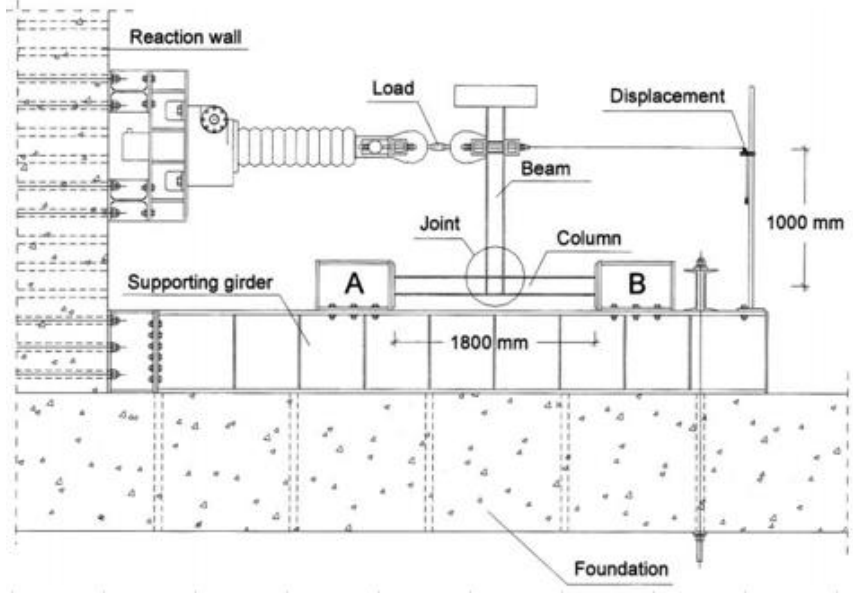

Fig. 12. Practical location of beam to column connection specimen test detailing [17].

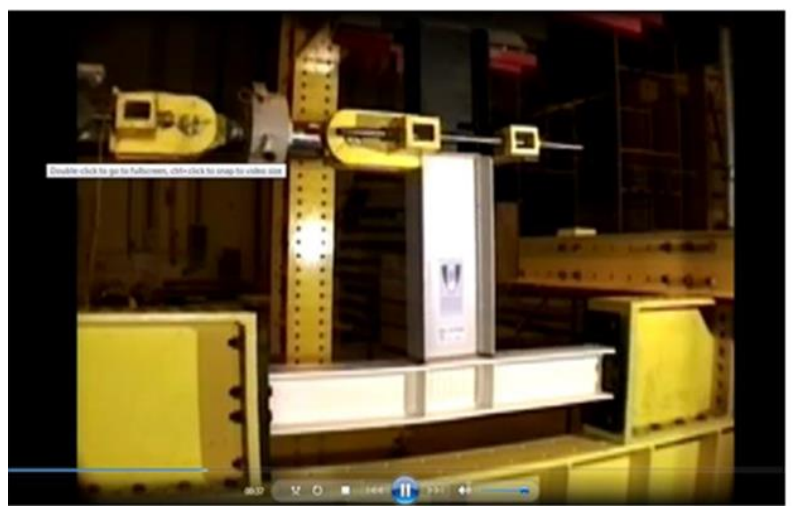

Fig. 13. Practical location of beam to column connection laboratory Capture (Calado, 2010-2014, per.comm.).

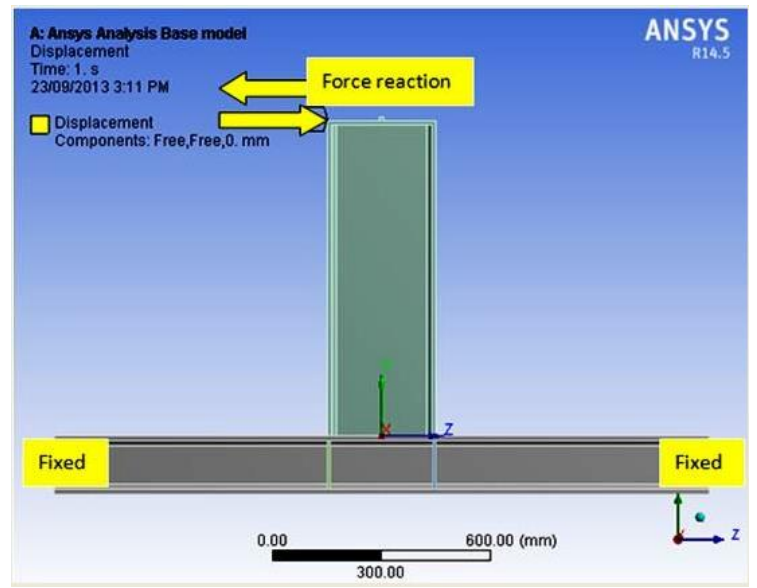

Fig. 14. Location of displacement and force reaction using Ansys 14.5.

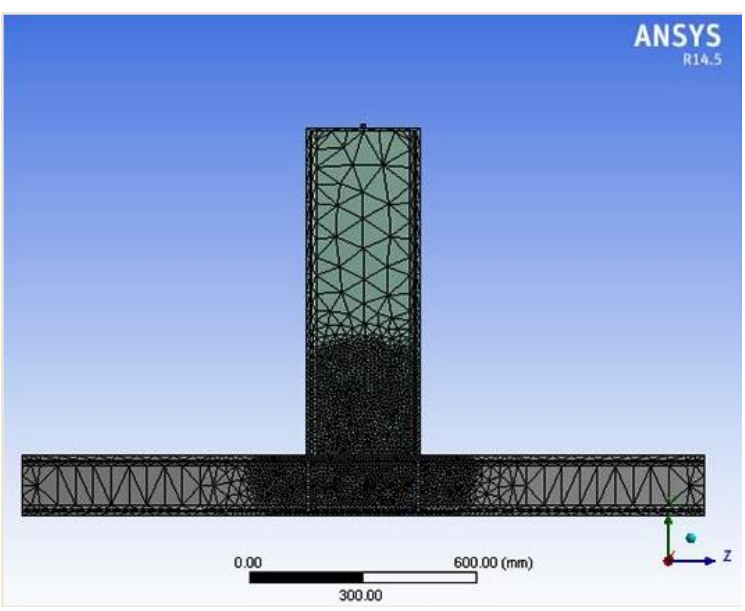

Fig. 15. Meshing and fine meshing using Ansys 14.5.

\section{A. Failure assessment diagram (FAD) based on cumulative} stress increments

The application of the FAD will be based on maximum stress, which is recommended [2], cumulative stress $(\sigma \mathrm{T})$ which is recommended [1], [2] and last half cycle stress range which is recommended [3]. In order to establish failure assessment diagram (FAD) curve, Equation (1) should be used.

Fig. 16-19 showed normal stress vs. No. of sub steps for BCC5 models, it is an analysis output evaluated at left beam flange at a critical point in the y-direction. It is used to calculate the stress ranges.

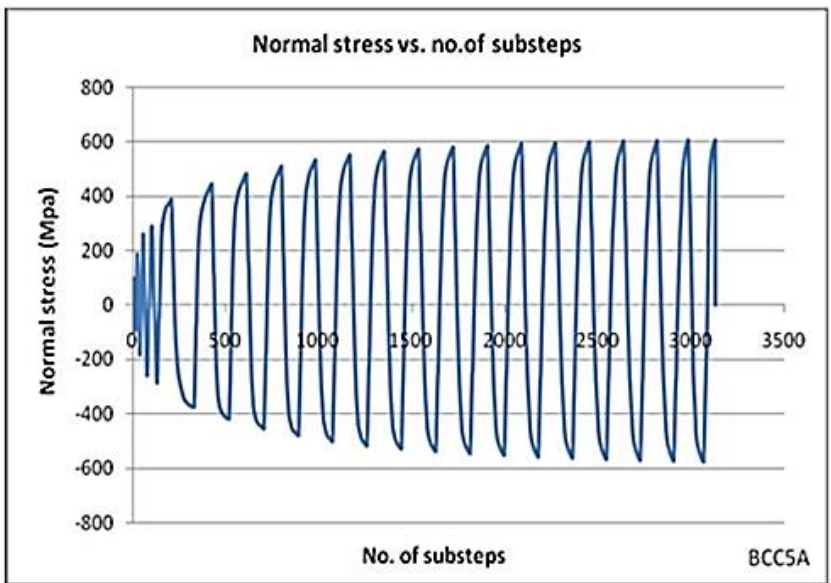

Fig. 16. Normal stress vs. no. of cycles for BCC5A model analysis

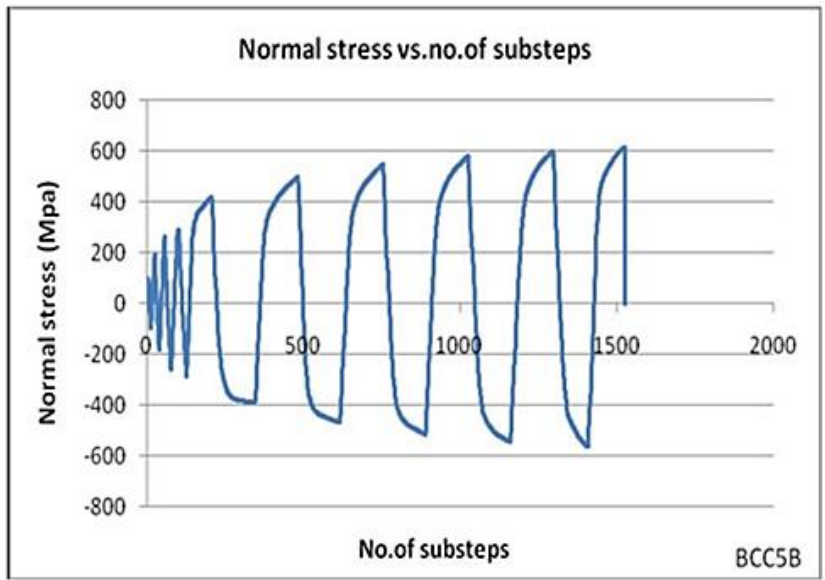

Fig. 17. Normal stress vs. no. of cycles for BCC5B model analysis.

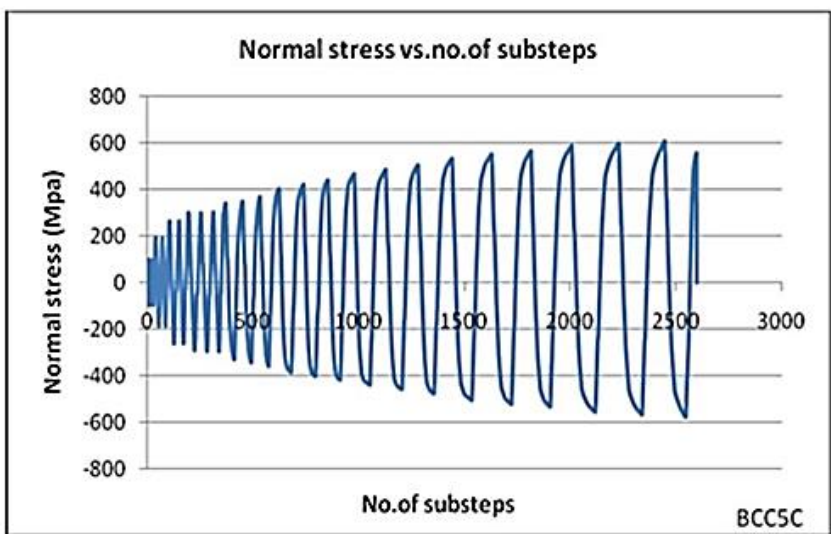

Fig. 18. Normal stress vs. no. of cycles for BCC5C model analysis. 


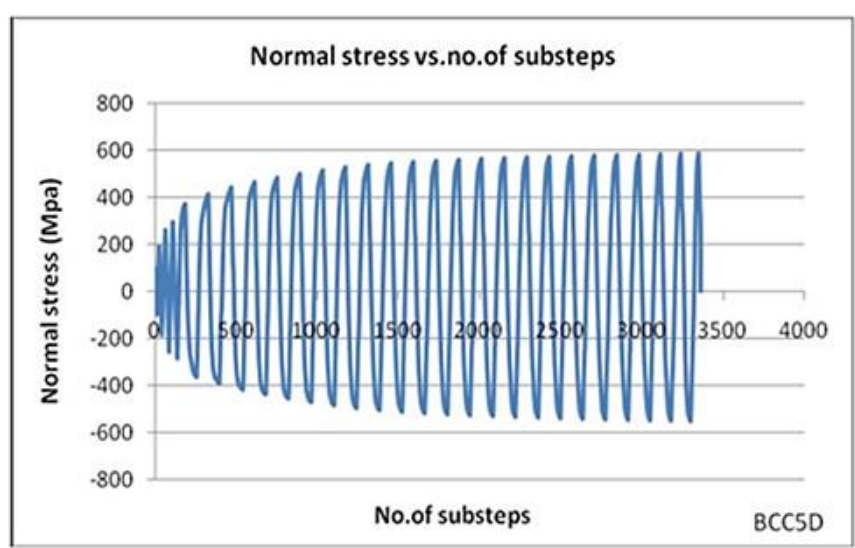

Fig. 19. Normal stress vs. no. of cycles for BCC5D model analysis.

\section{B. Calculations}

To establish the FAD curve, Equation (1) should be used to calculate $\mathrm{K}_{\mathrm{r}}$, by substituting $\mathrm{Lr}=\mathrm{L}_{\mathrm{r} \max }$

$$
\begin{aligned}
L_{r \max }= & \sigma_{u} / \sigma_{Y} \\
& =404.6 / 274.8=1.5, \text { therefore, } K_{r}=1
\end{aligned}
$$

$\exp =\mathrm{e}^{\mathrm{x}}$, inverse of $\mathrm{e}^{\mathrm{x}}=\ln \mathrm{e}^{\mathrm{x}}$.

To calculate $L_{r}$ and $K_{r}$ for BCC5 models, the following procedure explained using Cumulative stress $\left(\sigma_{\mathrm{T}}\right)$ :

$K_{f}=\sigma_{T} \sqrt{\pi} a_{0}(5)$

\section{where}

$\sigma_{\mathrm{u}}$ is the ultimate stress for beam flange obtained from the experiment (404.6 MPa);

$\sigma_{y}$ is yielding stress for flange obtained from experiment.

$\sigma_{y}=274.8 \mathrm{MPa}$;

$\sigma_{\max }$ is the maximum stress in the graph;

$\sigma_{\mathrm{T}}$ is the total stress range of the graph;

$K_{f}$ is the stress intensity factor $=\sigma_{\mathrm{T}} \sqrt{ } \pi \mathrm{a}_{\circ}$;

$\mathrm{a}_{\circ}$ is initial crack depth take it $0.2 \mathrm{~mm}$ [19];

$K_{c}$ fracture toughness $=\sqrt{ } \delta_{\mathrm{c}} \mathrm{E} \sigma \mathrm{y}[3]$;

$\delta_{\mathrm{c}}$ crack tip opening displacement, take it $=($ range is 0.1 to $1 \mathrm{~mm})$ [3];

$K_{c}$ (same for all specimens) $=\sqrt{ }(0.1 * 200000 * 274.8)$ to $\sqrt{ }$ (1*200000*274.8).

$$
K_{c}=2344 \mathrm{MPa} \mathrm{mm}{ }^{1 / 2} \text { to } 7413 \mathrm{MPa} \mathrm{mm}
$$

\section{BCC5A}

$L_{r \max }=\sigma_{\mathrm{u}} / \sigma_{\mathrm{Y}}=404.6 / 274.8=1.5$

$L_{r}=\sigma_{\mathrm{T}} / \sigma_{\mathrm{Y}}=16321.07 / 274.8=59$

$K_{f}=\sigma_{\mathrm{T}} \sqrt{ } \pi \mathrm{a}_{\circ}=16321.07 \sqrt{ }(3.14 * 0.2)=12893 \mathrm{MPa} \mathrm{mm}^{1} / 2$.
$K_{r}=K_{f} / K_{c}=12893 / 2344=5.4$

So, the point $\left(L_{r}, K_{r}\right)$ is $(59,5.4)$.

BCC5B

$L_{r}=\sigma_{\mathrm{T}} / \sigma_{\mathrm{Y}}=4646.31 / 274.8=17$

$K_{f}=\sigma_{\mathrm{T}} \sqrt{ } \pi \mathrm{a}_{\mathrm{o}}=4646.31 \sqrt{ }(3.14 * 0.2)=3670.58 \mathrm{Mpa} \mathrm{mm}^{1} / 2$.

$K_{r}=K_{f} / K c=3670.58 / 2344.35=1.5$

So, the point $(L r, K r)$ is $(17,1.5)$.

\section{BCC5C}

$L_{r}=\sigma_{\mathrm{T}} / \sigma_{\mathrm{Y}}=15038.51 / 274.8=55$

where $\sigma_{\mathrm{y}}$ is yield stress for flange $($ Exp. $)=274.8 \mathrm{MPa}$

$K_{f}=\sigma_{\mathrm{T}} \sqrt{ } \pi \mathrm{a}_{\mathrm{o}}=15038.51 \sqrt{ }(3.14 * 0.2)=11880.4 \mathrm{Mpa} \mathrm{mm}^{1} / 2$

$K_{r}=K_{f} / K_{c}=11880.4 / 2344.35=5.0$

So, the point $\left(L_{r}, K_{r}\right)$ is $(55,5.0)$.

BCC5D

$L_{r}=\sigma_{\mathrm{T}} / \sigma_{\mathrm{Y}}=22606.32 / 274.8=82$

where $\sigma_{\mathrm{y}}$ is yield stress for flange (Exp.) $=274.8 \mathrm{MPa}$ $K_{f}=\sigma_{\mathrm{T}} \sqrt{ } \pi \mathrm{a}_{\mathrm{o}}=22606.32 \sqrt{ }(3.14 * 0.2)=17858.9 \mathrm{Mpa} \mathrm{mm}^{1} / 2$. $K_{r}=K_{f} / K_{c}=17858.9 / 2344.35=7$.

So, the point $\left(L_{r}, K_{r}\right)$ is $(82,7.0)$.

To calculate $L_{r}$ and $K_{r}$ for BCC5 models based on maximum stress, and last half cycle stress ranges using the above procedure by substituting $\left(\sigma_{\max }\right)$ and $\left(\sigma_{\mathrm{L}}\right)$ instead of $\left(\sigma_{\mathrm{T}}\right)$ respectively.

Table II shows $\left(L_{r}, K_{r}\right)$ points for all BCC5 models by using maximum stress, cumulative stress $\left(\sigma_{\mathrm{T}}\right)$ and Last half cycle stress ranges.

Fig. 20 shows the results plotted on BS7910 Level 2a FAD for CTOD $=0.1$, representing in Table II.

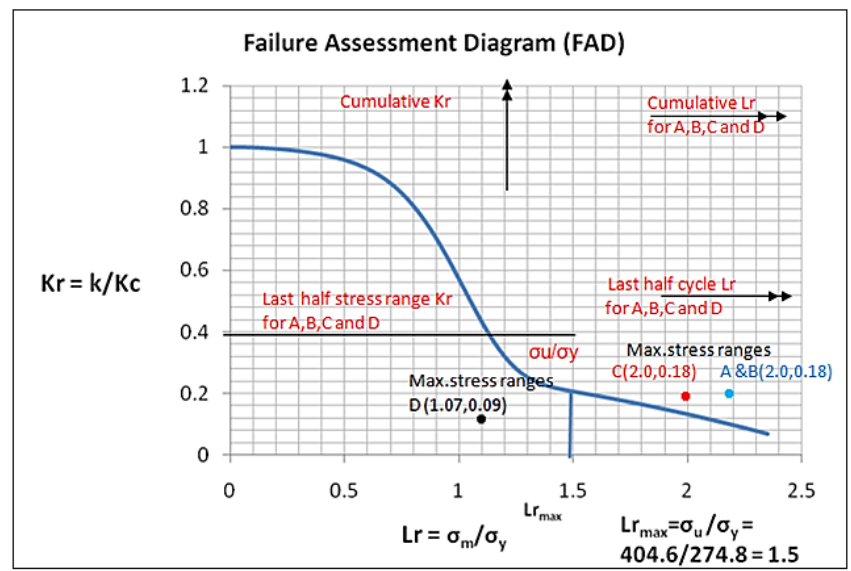

Fig. 20. Results plotted on BS7910 Level 2a FAD for CTOD $=0.1$.

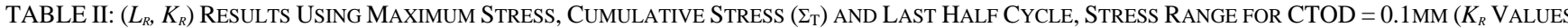
WOULD BE 0.31 TIMES THESE VALUES FOR CTOD = 1MM)

\begin{tabular}{ccccccc}
\hline $\begin{array}{c}\text { Specimen } \\
\text { No. }\end{array}$ & $\begin{array}{c}\text { Max. Stress } \\
\left(\sigma_{\max }\right) \mathrm{MPa}\end{array}$ & $\begin{array}{c}\text { Max. Stress } \\
\left(L_{r}, K_{r}\right)\end{array}$ & $\begin{array}{c}\text { Cumulative } \\
\text { Stress Ranges } \\
\left(\sigma_{\mathrm{T}}\right) \mathrm{MPa}\end{array}$ & $\begin{array}{c}\text { Cumulative } \\
\text { Stress Ranges } \\
\left(L_{r}, K_{r}\right)\end{array}$ & $\begin{array}{c}\text { Last Half Cycle } \\
\text { Stress Ranges }\left(\sigma_{\mathrm{L}}\right)\end{array}$ & $\begin{array}{c}\text { Last Half Cycle } \\
\text { Stress Ranges } \\
\left(L_{r}, K_{r}\right)\end{array}$ \\
\hline BCC5A & 606.45 & $(2.2,0.19)$ & 16321.07 & $(59,5.4)$ & 1158.49 & $(4.2,0.37)$ \\
BCC5B & 611.8 & $(2.2,0.2)$ & 4646.31 & $(17,1.5)$ & 1129.12 & $(4.1,0.38)$ \\
BCC5C & 553.6 & $(2.0,0.18)$ & 15038.51 & $(55,5.0)$ & 1154.37 & $(4.2,0.39)$ \\
BCC5D & 294.05 & $(1.07,0.09)$ & 22606.32 & $(82,7.0)$ & 1123.52 & $(4.1,0.37)$ \\
\hline
\end{tabular}




\section{DISCUSSIONS}

The results suggest that, if a FAD is to be used to indicate failure, then both $L_{r}$ and $K_{r}$ should be based on the maximum stress. The cumulative value gives $L_{r}$ and $K_{r}$ that are extremely large. The last stress range could be consistent with the FAD if the Crack Tip Opening Displacement (CTOD) of the test specimen was about $1 \mathrm{~mm}$ rather than $0.1 \mathrm{~mm}$ [3], recommended that CTOD should be between $0.1 \mathrm{~mm}$ to 1 $\mathrm{mm}$. Although a value of $1 \mathrm{~mm}$ is quite high it might have been achieved as a result of the heating effect of the large stress ranges. Note that $\sigma_{\mathrm{u}}$ has been exceeded, in three numerical models (BCC5A, BCC5B, and BCC5C) as shown in Fig. 20, $\sigma_{u}$ is engineering stress (based on the forces and the initial dimensions). The results calculated by the FE software are true stresses (based on the forces and the reduced thicknesses that result from large tensile strains). Therefore, the calculated (true) stresses can exceed the engineering value of $\sigma_{\mathrm{u}}$. Cyclic loading can also shift the stress/strain curve and increase or decrease the true $\sigma_{\mathrm{u}}$. This is possible as a result of the applied displacement rather than applied force in the experiments. The dynamic response in a real earthquake could be somewhere between that from an applied displacement and an applied force, so it would not be sensible to design for strains larger than those recommended in BS7910 for ordinary loading without studying this in more detail.

Note that no allowance for an increase in crack size caused by static load stable crack growth or fatigue has been taken into account. These effects would increase the $K_{r}$ value. Also, no increase in $K_{c}$ as a result of stable crack growth has been estimated, this would decrease the $K_{r}$ value. This calculation should be performed in addition to the fatigue calculations (Coffin Manson or crack growth) to ensure that the structure does not fail by fast fracture before the number of cycles predicted by the fatigue analysis is achieved. If sufficient information was available about the $\mathrm{J}$-integral resistance ( $\mathrm{J}$ $\mathrm{R})$ performance of the steel then the fatigue crack growth, table crack growth and FAD calculations could be integrated.

\section{CONCLUSIONS}

The following conclusions can be drawn:

1. Applying BS7910 FAD to the maximum stress for the $K_{r}\left(K\right.$ applied / $K_{c}$ critical $)$ calculation appears to work well. In the experiments, large values of $L_{r}$ (Applied stress / Yield stress) were obtained, but these are probably a result of the displacement-controlled experiment, so in the absence of further information $L_{r}$ should be limited in the way specified [2].

2. An initial defect size is required for the calculation. A crack size of $0.2 \mathrm{~mm}$ was used for this work. Depending on the fatigue calculations, it is possible to update this cycle by cycle. In that case, the maximum $K_{r}$ could occur later in a time history with a larger crack size $(d a)$ smaller stress than the maximum stress.

3. This work demonstrates how the computed reference stress is used to obtain the plastic collapse ratio $\left(L_{r}\right)$. It also shows how the analysis is used to obtain the stress intensity and the brittle fracture ratio $\left(K_{r}\right)$. Then these ratios give the location of the evaluation point on the FAD to indicate structural failure or safety.

4. The FAD point is important to evaluate an existing crack found during the inspection. It is also important to evaluate the end-of-life critical crack size for a fatigue crack growth analysis. Hence, Ansys could be used by engineers and designers to compute the CTOD needed for the calculation of the reference stress and stress intensity for the specific crack location and the specific structural component geometry.

5. It is expected that the CTOD will be in the range of 0.1 to $1 \mathrm{~mm}$. Even still the pipeline assessment method DET NORSKE VERITAS is very pessimistic in comparison with the option 2 curves [20].

6. Failure assessment diagram (FAD) curve to classify situations of structure safe or unsafe. The points under the FAD curve indicate that the cracks are acceptable, and the evaluation points above the FAD curve indicate cracks that could lead to structural failure. Hence, a point on the FAD curve indicates a critical crack on the verge of failure, which can be useful to determine the size of the predicted critical crack.

7. The BS7910:2013 solutions are sufficiently accurate for small defects but become very conservative when large cracks develop.

\section{ACKNOWLEDGMENT}

The author would like to acknowledge the fact that this paper was carried out in collaboration with the author's Supervisor Prof Nigel Barltrob at the University of Strathclyde with the assistance of Prof Luis Calado at the University of Lisbon. The assistance of Dr. Philip Esper in reviewing this paper is appreciated.

\section{REFERENCES}

[1] Guide to methods for assessing the acceptability of flaws in metallic structures, BS7910- 2005

[2] Guide to Methods for Assessing the Acceptability of Flaws in Metallic Structures, BS 7910:2013+A1-2015.

[3] Fracture control for pipeline installation methods, introducing cyclic plastic strain, DET NORSKE VERITAS (DNV) DNV-RP-F108-2006.

[4] C. Tipple and G. Thorwald. (2012). Using the failure assessment diagram method with fatigue crack growth to determine leak before rupture. SIMULIA customer conference.

[5] P. Ipiñac, A. Marcos, Berganta, A. Alejandro, Yawny, and E. Juan. (2015). Failure Assessment Diagram in Structural Integrity Analysis of Steam Generator Tubes. International Congress of Science and Technology of Metallurgy and Materials, SAM - CONAMET - 2013. Procedia Materials Science 8. Science Direct. [Online]. Available: www.sincedirect.com.

[6] A Joint API/ASME Fitness-for-Service Standard for Pressurized Equipment, API 579-1/ASME FFS-1 -2007.

[7] T.L. Anderson, Fracture Mechanics Fundamentals and Applications, 3rd ed. Taylor \& Francis group, Boca Raton, 2005, pp. 453-455. ISBN10:0-8493-1656-1.

[8] Fitness-for-service, American Petroleum Institute/ASME, Washington DC API 579-1/ ASME FFS-1 -2016.

[9] V. Pillai, A. Kolios and S.T. Lie. (2019). Failure assessment of cracked uni-planar square hollow section T-, Y- and K-joints using the new BS 7910:2013+A1:2015. Arch Appl Mech 89, 835-845 -2019 [online]. Available: https://doi.org/10.1007/s00419-018-1423-5.

[10] R. Ainsworth, M. Gintalas, M. Sahu, J. Chattopadhyay and B. Dutta. (2016). Application of failure assessment diagram methods to cracked straight pipes and elbows. International Journal of Pressure Vessels and Piping. Elsever. Volume 148. [Online]. Available: https://doi.org/10.1016/j.ijpvp.2016.10.005. 
[11] Assessment of the integrity of structures containing defects, Revision 4, including subsequent updates to Amendment 11, R6-2015. EDF Energy Generation, Gloucester, UK.

[12] Q. Yann, H. Chien-Hua and Chi-Fang L. (2013). Fracture resistance of ship longitudinal members including fatigue crack, ASME International Offshore and Arctic Engineering, OMAE, 32nd, June 914, Nantes, France.

[13] H. J. Hoh, J. H.L. Pang and Tsang K. S. (2018). Failure Assessment Diagram (FAD) analysis of fatigue test results for X65 welded joints. MATEC Web of Conferences, 165, 21011 [online]. Available: https://doi:10.1051/matecconf/201816521011.

[14] K. Konstantinos, H. Isabel, and M. Mahmoud. (2018). Validation of BS7910: assessing the integrity of pipes containing axial flaws. Procedia Structural Integrity 13, Elsevier.

[15] S. Lie. and V. Pillai, Safety Assessment of Damaged Multi-planar Square Hollow Section Welded Joints Using the New BS 910:2013+A1:2015. Advances in Applied Sciences. Vol. 4, No. 1, 2019 pp.11-22. [Online]. Available: https://doi 10.11648/j.aas.20190401.12

[16] S. Montassir, K. Yakoubi, H. Moustabchir, A. Elkhalfi, K. R. Dipen and I. Catalin. (2020), Analysis of Crack Behaviour in Pipeline System Using FAD Diagram Based on Numerical Simulation under XFEM, Appl. Sci. 10, 6129. [Online]. Available: www.mdpi.com/journal/applsci.

[17] E. Male, L. Calado and De Luca. (2003). An Experimental investigation on European welded connections. ASCE 129, Journal of Structural Engineering, 07339445, pp. 1301-1311.

[18] W. Aboalriha, N. Barltrop and L. Calado, (2018). "Prediction of low cycle fatigue life of steel welded connection subjected to high cyclic strains," presented at the ICCIE, March 13-15, 2018. Ras Al Khaimah, UAE.

[19] Guide to fatigue design and assessment of steel structures, BS76082014.

[20] Offshore standard, submarine pipeline system, DET NORSKE VERITAS (DNV) DNV-OS-F101-2012. [Online]. Available: http://www.dnv.com.

[21] Guide to methods for assessing the acceptability of flaws in metallic structures, BS7910- 2013.

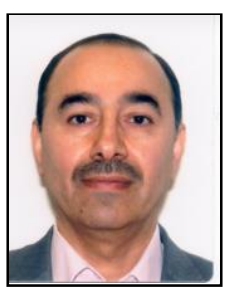

W. Aboalriha was born on 01- 07-1962 in Iraq.

And he was awarded a $\mathrm{PhD}$ in civil an environmental Engineering from University of Strathclyde, UK, Glasgow, 2015.

His MSc in structural engineering and foundations obtained from University of Westminster, UK, London, 1999.

His undergraduate degree BEng (Hons) in civil engineering obtained from University of Westminster, UK, London, 1997.

In addition, Dr Aboalriha is a member of the Society for Earthquake and Civil Engineering Dynamics (SECED), and also, he is a Member of European Association for Earthquake Engineering (EAEE) 